\title{
Epispadias in a Child with Intact Prepuce: A Rare Congenital Abnormality
}

\author{
Abubakar Maina Waziri', Babagana Mustapha Abubakar2*, Sani Adamu3, \\ Ibrahim Eneye Sulaiman', Mohammed Gashua² \\ ${ }^{1}$ Department of Surgery, Dr. Hassan's Clinic and Diagnostic Center, Abuja, Nigeria \\ ${ }^{2}$ Department of Surgery, Federal Medical Centre, Nguru, Nigeria \\ ${ }^{3}$ Department of Surgery, Federal University Teaching Hospital, Gombe, Nigeria \\ ${ }^{4}$ Department of Surgery, Aminu Kano Teaching Hospital/Bayero University, Kano, Nigeria

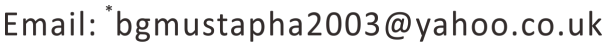

Received 29 January 2016; accepted 5 March 2016; published 8 March 2016

Copyright (C) 2016 by authors and Scientific Research Publishing Inc.

This work is licensed under the Creative Commons Attribution International License (CC BY).

http://creativecommons.org/licenses/by/4.0/

(c) (i) Open Access

\section{Abstract}

Epispadias is a rare genitourinary malformation, more so is epispadias with intact prepuce. Incidence of epispadias with intact prepuce is not known however, there are few case reports and a case series. We present a 5-year-old boy brought to our facility by his parent for circumcision. Further evaluation revealed a short penis with broad base and intact prepuce. The preputial slit was dorsally oriented. On retracting the prepuce, there was corona epispadias with wide and healthy urethral plate. No meatal stenosis or chordee noticed. Other findings were normal. He had epispadias repair. The postoperative period was uneventful. Three months after operation, the prepuce was easily retractable over the penis and the penis was cosmetically acceptable.

\section{Keywords}

Epispadias, Intact Prepuce, Epispadias Repair, Congenital Genito-Urinary Abnormality

\section{Introduction}

Epispadias is abnormal congenital opening of the urethra on the dorsum of the penis. It is believed to be a milder form of extrophy-epispadias complex which includes cloacal extrophy, bladder extrophy and epispadias. It is a rare genitourinary malformation, more so is epispadias with intact prepuce. Incidence of isolated epispadias is put at 2.4 per 100,000 birth [1] and 70\% are complete epispadias. Incidence of epispadias with intact prepuce is not known however there are few case reports [2]-[5] and a case series [6]. We present an unusual case of coro-

\footnotetext{
${ }^{*}$ Corresponding author.
} 
na epispadias, in a 5-year-old boy with intact prepuce.

\section{Case Report}

A 5-year-old boy brought to our surgical outpatient clinic for circumcision. There was no complaint by the parent about the appearance of the child's external genitalia. However mother had noticed upward direction of his urinary stream and occasional ballooning of the prepuce during micturition. There is no history of urinary incontinence, straining on micturition or recurrent per urethral discharge. No other congenital anomaly noticed and no past history of surgery. Pregnancy and delivery were supervised and were uneventful. He is product of full-term gestation and has normal developmental milestone.

The examination of the external genitalia revealed short penis with broad base. The prepuce was intact with the preputial slit dorsally oriented (Figure 1). On retracting the prepuce, there was coronal epispadias with wide and healthy urethral plate. No meatal stenosis or chordee noticed (Figure 2). He has a well-developed scrotum with both testes intrascrotal and were normal. A diagnosis of corona epispadias was made.

Abdomino-pelvic ultrasound scan, complete blood count, haemoglobin genotype and electrolyte, urea and creatinine were normal.

Urodynamic study was not performed as there was no suspicion of vesicoureteric reflux or reduced bladder capacity [6].

He had epispadias repair. A U-shaped incision was made with limbs of the $U$ at the edge of the urethral plate and the curve at the proximal end of the epispadias. The urethral plate was tubularised over size $10 \mathrm{~F}$ urethral catheter using Vicryl 5/0 suture. The two corporal bodies were approximated over the reconstructed urethra. The prepuce was reconstructed (Figure 3). No circumcision or supra-pubic cystostomy was done. Catheter was removed on the tenth post-operative days. He was able to void with anteriorly directed urinary stream.

At 3-month post-operative review, the child was able to void with good stream of urine. No fistula or other complication noted. The prepuce is easily retractable over the penis. The penis is cosmetically acceptable.

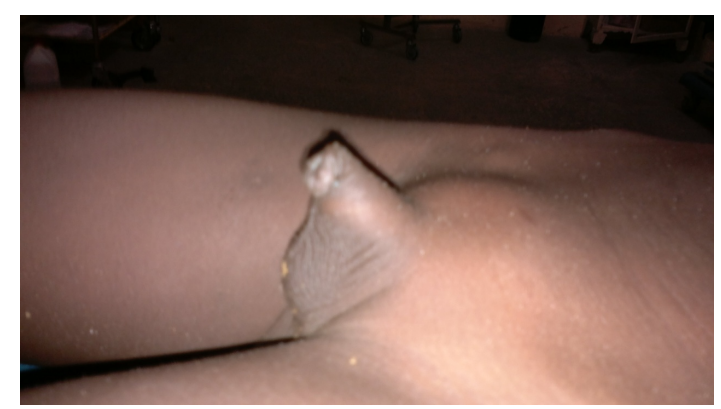

Figure 1. An intact prepuce with the preputial slit dorsally oriented.

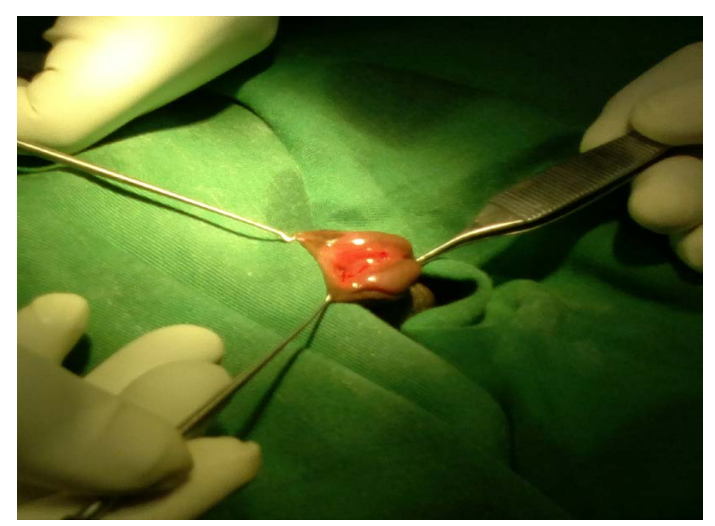

Figure 2. Coronal epispadias with healthy and wide urethral plate. 


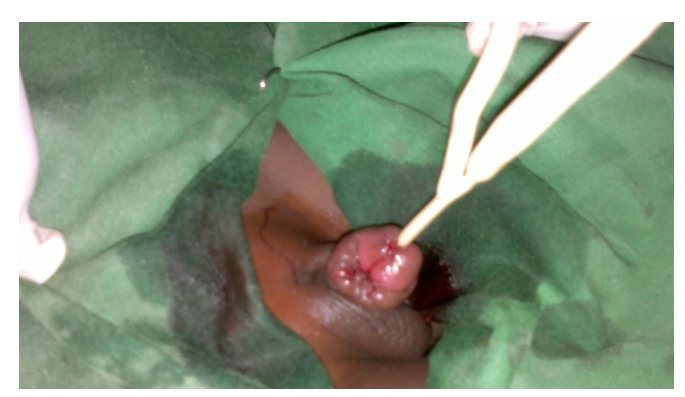

Figure 3. Immediate postoperative appearance after reconstruction.

\section{Discussion}

The incidence of isolated epispadias is put at 2.4 per 100,000 birth [1] and 70\% are complete epispadias.

It is usually associated with extrophy of the bladder in $90 \%$ of the cases. Typically, epispadiasis associated with defective prepuce on the dorsal aspect of the penis and redundant prepuce on the ventral aspect of the penis. Epispadias with intact prepuce as in this reported case is extremely rare. It incidence is not known however there are few case reports [2] [4] [5] [7]-[10] and a case series [6].

Various theories have been put in place to describe the development of the urethra but there are still controversies about the development of prepuce [11]-[13] and its relationship with the development of urethra [14]. Many authors [12] [13] quote Retterer (1885-1915) as the first to describe development of the prepuce as combination of preputial folding and the ingrowth of a cellular lamella. This in-growth creates the prepuce, the glans penis, the corona, and the coronal sulcus mucosa. Subsequently, Raghavaiah stated that the prepuce developed from ring of ectoderm that forms just proximal to the developing glans penis, this later advances over the corona and covers the glans entirely [9].

Most of these theories can explain typical epispadias but there is still no good explanation about epispadias with intact prepuce [5]. This make some authors [8] [15] to believe that epispadias with intact prepuce is as a result of developmental arrest in terms of non-closure of the urethral plate. They further stated that the presence of a dorsally directed preputial opening, the absence of frenulum on the glans and incomplete penile raphe are further evidences of an abnormal development. McCahill et al. in an attempt to explain epispadias with intact prepuce stated that there is an active growth of mesenchyme between the preputial fold and the glandular lamella, which transports the fold distally until it covers the glans completely even if there is defective glanular urethra development [7]. However, this has not explained corona or penile epispadias with intact prepuce. Moreover, because most of the reported cases of epispadias with intact prepuce were glanular, many authors equate it with mega-meatus intact prepuce hypospadias [5].

There may not be any complain by the parent to suggest this condition. The diagnosis is usually missed due to the apparently normal looking penis. Most cases are discovered when the child is presented for circumcision as seen in the index case. Features like upward directed urinary stream, ballooning of the prepuce while micturiating, are not constant and may not be taken very serious by most parents. As seen in the index case, the mother noticed the upward directed urinary stream but she never gave it any importance. Deviation of the preputial opening upward towards the dorsal aspect of the penis, absence of frenulum line on the glans, horizontal termination of the raphe phallus close to the glans, phimosis, broad base phalus, spade like glans, splitted corpora cavernosal and a depression between the corpora bodies are some of the signs that can be seen in this condition [2] [3] [5]-[9]. Because the diagnosis is clinical, not many investigations are usually required. Abdomino-pelvic ultrasound scan done to this patient is to rule out other congenital urinary tract abnormalities, which are the commonest association of this condition.

Surgery gives acceptable functional and cosmetic outcome. There are many surgical procedures described for treatment of epispadias. For epispadias with intact prepuce, especially coronal or glanular, simple approximation of the glans penis with or without circumcision may be just what is needed to give good outcome as seen in this case. Though the follow up is short, postoperative appearance and urinary stream are satisfactory.

This condition should be born in mind. Underreporting maybe present, [6] especially in communities where circumcision is not consistently practiced. Whereas, it is easier detected in countries where most males undergo 
circumcision.

\section{Conclusion}

Epispadias with intact prepuce is a rare congenital anomaly of the external genitalia. Presentation may be late due to apparently normal looking penis. Examination of the penis before circumcision cannot be overemphasized, as this may be the only opportunity to pick this anomaly.

\section{References}

[1] (1987) Epidemiology of Bladder Exstrophy and Epispadias: A Communication from the International Clearinghouse for Birth Defects Monitoring Systems. Teratology, 36, 221-227. http://dx.doi.org/10.1002/tera.1420360210

[2] Bhattacharya, V., Sinha, J.K. and Tripathi, F.M. (1982) A Rare Case of Epispadias with Normal Prepuce. Plastic and Reconstructive Surgery, 70, 372-3724. http://dx.doi.org/10.1097/00006534-198209000-00016

[3] Krishna, A. and Iyer, P.U. (1989) Epispadias with Complete Non-Retractile Prepuce. Indian Pediatrics, 26, $1055-1056$.

[4] Sina, A. and Alizadeh, F. (2011) Concealed Male Epispadias: A Rare Form of Penile Epispadias Presenting as Phimosis. Urology Journal, 8, 328-329.

[5] Maitama, H.Y., Ahmed, M., Bello, A. and Mbibu, H.N. (2012) Epispadias with Complete Prepuce: A Rare Anomaly. African Journal of Urology, 18, 90-92. http://dx.doi.org/10.1016/j.afju.2012.07.001

[6] Bos, E.M., Kuijper, C.F., Chrzan, R.J., Dik, P., Klijn, A.J. and de Jong, T.P. (2014) Epispadias in Boys with an Intact Prepuce. Journal of Pediatric Urology, 10, 67-73. http://dx.doi.org/10.1016/j.jpurol.2013.06.005

[7] McCahill, P.D., Leonard, M.P. and Jeffs, R.D. (1995) Epispadias with Phimosis: An Unusual Variant of the Concealed Penis. Urology, 45, 158-160. http://dx.doi.org/10.1016/S0090-4295(95)97778-3

[8] Merlob, P., Mor, N. and Reisner, S.H. (1987) Epispadias with Complete Prepuce and Phimosis in a Neonate. Clinical Pediatrics (Phila), 26, 43-45. http://dx.doi.org/10.1177/000992288702600108

[9] Raghavaiah, N.V. (1976) Epispadias Associated with Phimosis. Journal of Urology, 116, 671-672.

[10] Sarin, Y.K. and Sinha, A. (2001) Concealed Epispadias. Indian Journal of Urology, 17, 183-184.

[11] Jones, F.W. (1910) The Development AND Malformations of the Glans AND Prepuce. British Medical Journals, 1, 137-138. http://dx.doi.org/10.1136/bmj.1.2559.137

[12] Cold, C.J. and Taylor, J.R. (1999 The Prepuce. BJU International, 83, 34-44. http://dx.doi.org/10.1046/j.1464-410x.1999.0830s1034.x

[13] Glenister, T.W. (1956) A Consideration of the Processes Involved in the Development of the Prepuce in Man. British Journal of Urology, 28, 243-249. http://dx.doi.org/10.1111/j.1464-410X.1956.tb04763.x

[14] Favorito, L.A., Balassiano, C.M., Costa, W.S. and Sampaio, F.J. (2012) Development of the Human Foreskin during the Fetal Period. Histology and Histopathology, 27, 1041-1045.

[15] Ebert, A.K., Reutter, H., Ludwig, M. and Rosch, W.H. (2009) The Exstrophy-Epispadias Complex. Orphanet Journal of Rare Diseases, 4, 23. http://dx.doi.org/10.1186/1750-1172-4-23 